\title{
Os latossolos amarelos, álicos, argilosos dentro dos ecossistemas das bacias experimentais do INPA e da região vizinha (1)
}

\author{
Armand Chauvel ( ${ }^{2}$ )
}

\begin{abstract}
Resumo
O estudo refere-se aos latossolos amarelos, álicos, argilosos, os mais extensivamente representados nas bacias hidrográficas da ZF-02. Esses solos ocupam as superfícies dos platôs. O estádio "de referência" sob floresta é caracterizado pela presença de um horizonte médio, poroso, fortemente microagregado, situado entre dois horizontes menos porosos. Esse perfil caracteriza-se, ainda, por uma distribuição regular e profunda da matéria orgânica. Nos solos sob capoeira, a distribuição dos vazios e da matéria orgânica é bem diferente, entretanto, ela evolui com a idade no mesmo sentido do perfil inicial. O solo sob cultura mecanizada apresenta uma baixa porosidade na parte superior $e$ uma diminuição progressiva da matéria orgânica até $45 \mathrm{~cm}$.
\end{abstract}

\section{INTRODUÇÃo}

Os solos constituem um componente nos meios florestais subequatoriais: sua estrutura determina a permeabilidade ao ar e a água, assim como a possibilidade de desenvolvimento das raízes e dos animais cavadores, enquanto que uma parte importante dos nutrientes é reciclada e/ou conservada no solo.

Quando do estudo experimental empreendido pelo INPA nas pequenas bacias, com o objetivo de determinar as reações destes sistemas naturais às modificações provocadas por fatores bióticos e abióticos (desmatamento), procurou-se dar maior atenção à evolução destes solos, mais particularmente à sua estrutura e suas reservas em nutrientes.

O presente estudo versa sobre os solos mais representativos em extensão nestas bacias experimentais. Tem por objetivo definir seu estadio inicial "de referência", a fim de apreciar seu papel no ecossistema florestal, estabelecer comparações com outras zonas subequatoriais e, sobretudo, avaiiar os efeitos dos diversos tipos de intervenção humana (desmatamento e cultivo).

\section{MATERIAIS E MÉTODOS}

\section{CARACTERÍSTICAS GERAIS DA ZONA ESTUDADA}

Os solos estudados estão situados na reserva da Estação Experimental de Silvicultura Tropical do INPA, a $60 \mathrm{~km}$ ao norte de Manaus e na região vizinha.

O material original desses solos é composto pelos sedimentos terciários do "Grupo Barreiras" que são, neste caso, essencialmente constituidos de minerais resistentes a alteração, tais como a caolinita, o quartzo, os óxidos e hidróxidos de ferro e alumínio.

O modelado é caracterizado por baixos "platôs", localmente dissecados pela rede hidrográfica, ligados por vertentes convexas a vales de fundo chato. Os latossolos estudados ocupam as superfícies desses "platôs".

A pluviosidade média anual é da ordem de $2100 \mathrm{~mm}$ (Villa Nova et al., 1976). O clima é caracterizado por uma temperatura sempre elevada $\left(26-27^{\circ} \mathrm{C}\right)$ e pela alternância de uma longa estação úmida, durante a qual o excedente hídrico atinge aproximadamente $900 \mathrm{~mm}$, e uma estação seca de 5 meses nitidamente deficitária (de junho a outubro: déficit de $360 \mathrm{~mm}$ ).

Toda a região está coberta pela floresta tropical úmida de baixa altitude. .

(1) - Pesquisa desenvolvida com apoio financeiro da OEA, em colaboração com o Instituto Nacional de Pesquisas da Amazônia, Manaus, AM.

(2) - Missão ORSTOM França e Instituto de Geociências da USP, São Paulo, SP. 
São latossolos amarelos, cauliníticos, álicos (Brasil - Projeto RADAM, 1976, 1981; Falesi, 1969; Ranzani, 1980) e correspondem aos ferralíticos típicos fortemente dessaturados no horizonte $B$, segundo a classificação francesa (CPSC, 1967) e ao "aplic acrorthox" da So'I Taxonomy (1973).

O perfil n. 1 encontra-se sob floresta primária na parte plana, cuja declividade é praticamente nula.

O perfil esquemático é o seguinte:

0 . $2-0 \mathrm{~cm}$ : camada contínua formada de folhas e galhos em vários estágios de decomposição. Concentrações localizadas de raízes finas.

A1. 0-5 cm : Bruno amarelado (10 YR $7 / 4$ a 6/4 úmido) argila; estrutura moderada, pequena $\mathrm{e}$ média, granular e blocos subangulares; poros tubulares preenchidos por grāos muito pequenos, brunos; muito plástico e pegajoso; concentrações de raízes finas e médias no centímetro superior do horizonte; transição plana e gradual.

A3. $5-35 \mathrm{~cm}$ : Bruno amarelado (10 YR 6/4, úmido), com mosqueado distinto de matéria orgânica bruno claro acinzentado; argila; estrutura fraca, em blocos subangulares e angulares, média; ̣̣lástico e muito pegajoso; transição plana $\mathrm{e}$ gradual.

B1 $35-70 \mathrm{~cm}$ : Amarelo (10 YR 7/6 úmido), argila; estrutura fraca, com blocos angulares e subangulares, muito poroso com tubos finos e muito finos preenchidos por microagregados; plástico e pegajoso; algumas raízes finas; transição difusa.
YR 7/6, úmido); argila; estrutura fraca, localmente granular muito pequena; poroso, com tubos finos; friável, plástico e pegajoso; transição difusa.

B22 $150-230 \mathrm{~cm}$ : Amarelo avermelhado $(7.5$ YR $7 / 6$ úmido); argiīa, estrutura fraca, maciça e granular muito pequena; pouco poroso, com tubos finos; friável, plástico e pegajoso.

Observações: Nota-se a presença de alguns pedaços de carvão de madeira até $30 \mathrm{~cm}$ de profundidade, os cascalhos são praticamente inexistentes.

As frações areia e silte são da ordem de $10 \%$ no totál, constituidas principalmente de quartzo. A fração argila, dominante é constituída de coalinita $(80 \%)$, gibsita $(10 \%)$, goethita... As características analíticas principais são apresentadas no quadro 1 . Nota-se um gradiente textural nítido nos dez primeiros centímetros, que se torna muito fraco abaixo. O solo é ácido ( $\mathrm{pH}$ em torno de 4,5), ultrapassando o pH 5 apenas no horizonte B21. A soma de bases trocáveis é muito pequena em todos os horizontes. Os teores de ferro livre são vizinhos a $1,4 \%$ de $\mathrm{Fe}_{2} \mathrm{O}_{3}$.

As variações em torno deste perfil esquemático são muito fracas sob a floresta primária. Este tipo de solo pode, portanto, ser considerado como de "referência".

Algumas modificações importantes (em relação ao perfil tipo) são observadas sob as capoeiras recentes ou antigas.

$\mathrm{Na}$ capoeira recente ( 4 anos, perfil n. 2 ), nota-se, sob uma vegetação secundária com dominância da "imbaúba" (Cecropia sciadophylla), um espessamento da camada superficial de folhas em decomposição, que atinge 5 $\mathrm{cm}$ de espessura.

O horizonte $A 1$, de 0 a $13 \mathrm{~cm}$, é sobretudo marcado pelos efeitos de uma atividade biológica intensa (cupins, formigas, minhocas...); apresenta uma coloração mais bruna que no perfil de referência sob floresta (10 YR 4/2); 
numerosos tubos e canais, de dimensões milimétricas a centimétricas têm suas paredes revestidas de argila bruna; alguns, entre eles, estão preenchidos por dejetos da fauna; as raízes, de diversos tamanhos, são muito numerosas e orientadas sobretudo horizontalmente.

O horizonte $A 3$, de 13 a $30 \mathrm{~cm}$, de cor bruna amarelada clara (10 YR 6/4), apresenta, em seu conjunto uma estrutura maciça, mas é penetrado por uma porosidade tubular média e fina muito importante, progressivamente decrescente de cima para baixo; observamse numerosas raízes de todas as dimensões, assim como canais e ninhos de insetos, às vezes preenchidos por detritos orgânicos brunos; percebe-se, em torno de todas estas organizações de origem biológica, a presença de manchas difusas de cor mais escura..

O horizonte $\mathrm{B} 1$, de 30 a $60 \mathrm{~cm}$, amarelo (10 YR 7/6) contém numerosos tubos, de dimensões milimétricas, preenchidos por microagregados de terra bruna a bruna cinza.

Os horizontes B21 (de 60 a $120 \mathrm{~cm}$ ) e B22 $(120 \mathrm{~cm}$ e mais) enfim, amarelo avermelhado, são caracterizados por uma estrutura maciça dominante, recortado por volumes tubulares, milimétricos, ocupados por terra finamente agregada da mesma cor do horizonte, representando quase $30 \%$ do volume total.

Comparado ao perfil de referência, o latossolo observado sob capoeira recente, aparece caracterizado pelo aumento da acumulação superficial de detritos orgânicos, pelo transporte por "descensum" de uma parte dos constituintes provenientes da liteira, misturados com a terra e depositados ao nível dos horizontes B1 e B21, e enfim pelos efeitos, so. bre a porosidade, de uma intensa atividade biológica, que atinge o horizonte B21.

Os dados analíticos clássicos evidenciam algumas variações com relação ao perfil de referência sob floresta: ligeira diminuição do teor em argila no horizonte A1 e um fraco aumento deste teor no B1, provocando um aumento do gradiente textural - aumento do teor em matéria orgânica no horizonte $A 1 \mathrm{com}$ uma relação $\mathrm{C} / \mathrm{N}$ elevada $(16,4)$ que indica que o processo de humificação é parcial - acentuação da acidez no horizonte $\mathrm{A} 1 \mathrm{(pH}$ em torno de 4), aumento da soma de bases trocáveis ( $\mathrm{Ca}, \mathrm{Mg}$ e K) nos horizontes A1 e A3.

Parece se produzir depois de um desmatamento seguido de um só ciclo de cultivo, uma pequena acumulação de matéria orgânica e das bases trocáveis e uma ligeira mobilização da argila no interior do perfil.

$\mathrm{Na}$ capoeira antiga (35 anos, perfil $n .^{\circ} 3$ ), a vegetação florestal inicial é parcialmente regenerada, enquanto que as "imbaubas" (Cecropia sciadophyllaj tendem a desaparecer. A camada superficial torna-se menos espessa (3 $\mathrm{cm}$ ), fortemente decomposta, bruna escura (10 YR 3/3), explorada por numerosas raizes.

Os horizontes A1 $(0-10 \mathrm{~cm})$ e $A 3(10-30$ $\mathrm{cm}$ ) diferem daqueles do perfil de referência sob floresta primária, apenas pelas cores mais claras, bruno amarelado e amarelo (10 YR 6/4 e $8 / 6$ ) e por uma porosidade mais forte, de origem biológica.

O horizonte $\mathrm{B} 1(30-50 \mathrm{~cm})$, da mesma cor que no perfil de referência (10 YR 7/6), estrutura maciça, apresenta apenas uma porosidade tubular fina, bastante fraca.

Nos horizontes B21 $(50-120 \mathrm{~cm})$ e B22 (120 e mais) são ainda observados volumes tubulares, de dimensões milimétricas, preenchidos por materiais finamente agregados.

Por suas características morfológicas, este solo, antigamente cultivado, mas abandonado, há quase 35 anos, à floresta, se assemelha mais ao perfil de referência (sob floresta primária) que o aos solos sob capoeira recente.

Os dados analíticos clássicos não revelam uma diferença notável com o perfil de referência, sob floresta, a não ser no que concerne a soma de bases trocáveis, elevada no horizonte superficial mas muito fraca nos horizontes $\mathrm{B} 21$ e B22, a partir de $55 \mathrm{~cm}$.

Parece, aqui, que após a fraca redistribuição da argila e das bases trocáveis no perfil, devidas ao desmatamento, o solo evolui de novo para o estado de equilíbrio observado sob floresta primária.

As modificações mais importantes aparecem sobre o mesmo tipo de solo, desmatado mecanicamente e recentemente plantado com Hevea (CODEAGRO - BLOCO 95c - perfil 
n. 4). A superfície está, no geral desnudada, localmente recoberta por gramíneas. As plantas jovens de Hevea desenvolvem-se de forma irregular, e não formam um conjunto homogêneo. O perfil correspondente é o seguinte: o horizonte $A P$, de 0 a $15 \mathrm{~cm}$, de cor bruna e bruno cinza (10 YR $5 / 3$ a $5 / 2$ ), de textura argilosa, apresenta uma estrutura moderada, pequena, subangular, e uma porosidade tubular e fissural fina muito forte, sua transição com o horizonte $A 3$ é nítida. O horizonte $A 3$, de 15 a $33 \mathrm{~cm}$ é amarelo (10 YR 8/8), muito argiloso, de estrutura maciça, desfazendo-se em poliedros de dimensões centimétricas; a poros:dade é tubular fina e sobretudo fissural; as pequenas raízes revestem as superfícies das fissuras; nota-se a presença de alguns canais e cavidades biológicas preenchidos por terra bruna. A transição é piana e difusa com o horizonte B21 (de 33 a $50 \mathrm{~cm}$ ) amarelo a amarelo-vermelho $(7,5$ YR 7/8), muito argiloso, de estrutura maciça, recortado por numerosos canais e cavidades biológicas preenchidos seja por argila, seja por microagregados.

Passa-se progressivamente a um horizonte B22 (de 50 a $110 \mathrm{~cm}$ ) amarelo-vermelho, argiloso, de estrutura maciça, recortado por numerosos volumes tubulares, de dimensões milimétricas, preenchidos por um material finamente microagregado.

Do ponto de vista morfológico, o perfil se divide em duas partes:

- a primeira superficial, de $33 \mathrm{~cm}$ de espessura, cinza à amarela, muito argilosa, de estrutura subangular à maciça e porosidade essencialmente fissural, é bem diferente do conjunto dos horizontes $A 1$ e A3 observados sob floresta e sob capoeira;

- a segunda, abaixo de $33 \mathrm{~cm}$, constituida pelos horizontes B21 e B22, que se assemelham mais nitidamente aos horizontes equivalentes do perfil de referência.

Os dados analíticos clássicos põem em evidência, uma acidez máxima no horizonte A3 $(\mathrm{pH}, 4,3)$, mas inferior no horizonte $\mathrm{Ap}(\mathrm{pH}$ $4,7)$ e ao nível do horizonte $\mathrm{B} 22(\mathrm{pH} 5,2$ à 70-80 $\mathrm{cm})$; a soma de bases trocáveis apresenta um máximo superficial no horizonte $A p$ e os valores mais fracos abaixo.

\section{MÉTODOS DE CARACTERIZAÇÃo DOS SOLOS}

Esta caracterização consiste de início em uma análise estrutural (macroscópica e microscópica) da cobertura pedológica da bacia considerada.

Em cada um dos perfis precedentemente descritos, foram coletados, ao nível de cada horizonte, amostras orientadas que foram, em seguida, consolidadas, laminadas e observadas ao microscópio petrográfico.

Esta análise permitiu apreciar a importância relativa e a distribuição dos volumes ocupados pelos constituintes sólidos (argila, areia e matéria orgânica) e pelos vazios, em relação à atividade biológica.

Para avaliar mais precisamente os teores volumétricos (em matéria sólida, solução do solo, nutrientes...) efetuaram-se medidas de densidade aparente, umidade e densidade real, em várias centenas de amostras de $100 \mathrm{~cm}^{3}$, coletadas num cilindro, em cada um dos horizontes dos diferentes perfis estudados, 2 dias após uma chuva.

As densidades aparentes obtidas permitiram calcular, a partir dos dados de análise química, os teores volumétricos em matéria orgânica, nitrogênio, fósforo $\left(\mathrm{P}_{2} \mathrm{O}_{5}\right)$, bases trocáveis $(\mathrm{Ca}++, \mathrm{Mg}++$ e $\mathrm{K}+)$ e totais $(\mathrm{CaO}$, $\left.\mathrm{Mg0}, \mathrm{K}_{2} \mathrm{O}\right)$.

A fim de permitir uma confrontação com os dados relativos aos ecossistemas (biomassa...), os resultados foram expressos em quantidades de elementos simples (N, P, K, $\mathrm{Ca}, \mathrm{Mg}$ ), calculando-se as quantidades correspondentes a uma unidade de superfície ( 1 hectare) com uma profundidade de 1 metro.

Os principais dados utilizados para esta avaliação (quadro 1) são os seguintes: matéria orgânica (deduzida do carbono total, medido pela combustão do solo e dosagem do $\mathrm{CO}_{2}$ liberado) - nitrogênio - fósforo total (extração pelo $\mathrm{NO}_{3} \mathrm{H} 13 \mathrm{~N}$ ) e assimilável (método OLSEN) - bases trocáveis (extração com acetado de amônio a pH 7) - bases totais (dissolução pelo ataque tri-ácido). 


\section{Resultados}

OBSERVAÇÕES MICROSCÓPICAS

As microfotografias das amostras coletadas sob floresta primária, capoeira e plantações de Hevea figuram nas Estampas I, II, III.

Em todos os perfis, observa-se a grande dominância de um plasma argiloso, que ccnstitui o essencial da matéria sólida, enquanto que os grãos de areia (quartzo) são raros e dispersos. Deduz-se que não existe nestes solos um "esqueleto" arenoso capaz de constituir uma armação e assegurar a manutenção da macroporosidade. Esta só pode resultar, portanto, do estado de agregação do plasma (vazios interagregados), da existência de poros de origem biológica (tubos de raízes, canais e cavidades construídos pela fauna], ou ainda da formação de fissuras quando da retratação pela dessecação.
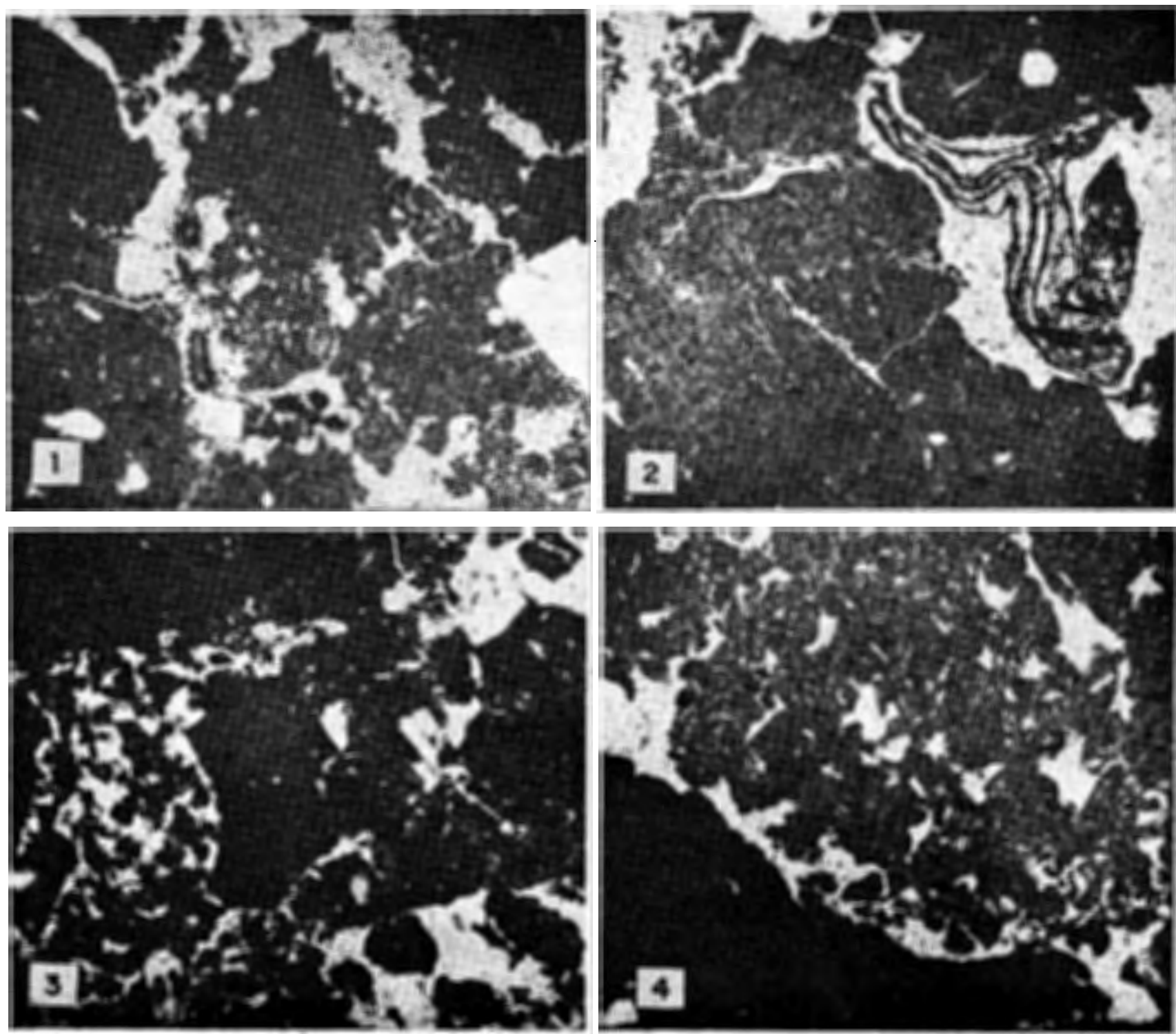

Est. 1 - Perfil 1. Floresta primária: 1] Horizonte A1. Indícios de atividade biológica forte. Numerosas raízes. Faunapedoturbação importante. Pequenos fragmentos de matéria orgânica; 2) Horizonte A3. O plasma argiloso forma uma massa contínua, cortado por algumas fissuras muito finas. Raiz fortemente contorcida, revelando uma dificuldade de penetração. 3) Horizonte B1. Volumes tubulares, ocupados por microagregados, que contêm fragmentos bruno-vermelhos de matéria orgânica; 4) Horizonte B2 1. Dois tipos de volumes nitidamente delimitados. Uma massa contínua, sem porosidade visível. Tubos de dimensões milimétricas, ocupados por uma terra finamente dividida. 
No conjunto, parece que o plasma argiloso tende naturalmente a formar uma estrutura contínua, não deixando lugar a uma porosidade visivel. Isto é devido provavelmente à fraca atividade coloidal da caolinita, e aos fracos teores em cimentos férricos nestes solos (Chauvel, 1981). Resulta, então, que só é mantida a porosidade criada por uma atividade biológica quase permanente, ou pelos fenômenos de retração ligados a fortes variações de umidade.

$O$ perfil n. 1 de referência, sob floresta (Estampa I) apresenta os seguintes aspectos:

- O horizonte A1 é parcialmente microagregado e bastante poroso; apresenta os indícios de uma atividade biológica forte: numerosas raízes, fauna-pedoturbação importante, pequenos fragmentos de matéria orgânica, de cor vermelho. bruna, misturados à argila de maneira homogênea .

- O horizonte A3 é muito mais compacto; o plasma argiloso forma uma massa contínua, cortado por algumas fissuras muito finas e sobretudo por tubos e cavidades biológicas. As raízes observadas nestes poros são às vezes fortemente contorcidas, o que revela uma certa dificuldade de penetração. A matéria orgânica está ainda presente sob forma de partículas muito finas, bruno-vermelhas, intimamente misturadas à argila.

- O horizonte B1 é mais poroso; observam-se, em uma massa argilosa contínua, numerosos tubos, de dimensões milimétricas, com preenchimentos biológicos constituídos de microagregados, que contém fragmentos de matéria orgânica bruno-vermelhos.

- O horizonte B21 apresenta dois tipos de volumes nitidamente delimitados: uma massa contínua, dominante, sem porosidade visível - tubos de dimensões milimétricas, ocupados por uma terra finamente dividida.

O perfil n. 2 sob capoeira recente é diferente: (Estampa II)
- O horizonte A1 é caracterizado pela presença de volumes muito porosos, contendo forte concentração de pequenos fragmentos vegetais em decomposição, misturados a excrementos da fauna ("fecal pellets" de $50 \mu \mathrm{m}$ de diâmetro) e a microagregados argilosos $(100 \mu \mathrm{m}$ de diâmetro), e percorridos por numerosas raízes pequenas. Estes volumes, fortemente bioturbados, estão separados uns dos outros por agregados argilosos poliédricos, grosseiros.

- O horizonte A3 apresenta uma estrutura contínua, recortada por volumes bioturbados contendo numerosas partículas orgânicas. Uma faixa de cor escura é visível na vizinhança e no exterior destes volumes; poderia corresponder ao depósito, à curta distância, de produtos resultantes da decomposição da matéria vegetal, ou ainda, ao desenvolvimento localizado de micro-organismos (cogumelos e/ou bactérias).

- O horizonte B1, apresenta apenás uma fraca porosidade, fina a muito fina, em uma massa argilosa contínua.

- O horizonte B21 é comparável ao observado no perfil de referência, sob floresta, caracterizado pela presença de tubos milimétricos, ocupados pela terra finamente dividida.

$O$ perfil n. 4 observado sob a plantação jovem de Hevea (após o desmatamento completo) apresenta um outro aspecto. (Estampa III)

- O horizonte Ap é constituido principalmente por um plasma argiloso contínuo, recortado por fissuras muito finas e, localmente, por alguns tubos e volumes microagregados.

- O horizonte A3 é igualmente compacto; observa-se sobretudo fissuras, dispostas obliquamente, e alguns raros vazios de origem biológica.

- O horizonte B21 é percorrido por numerosos canais de origem biológica, preenchidos por microagregados, dando lugar a uma porosidade importante. 

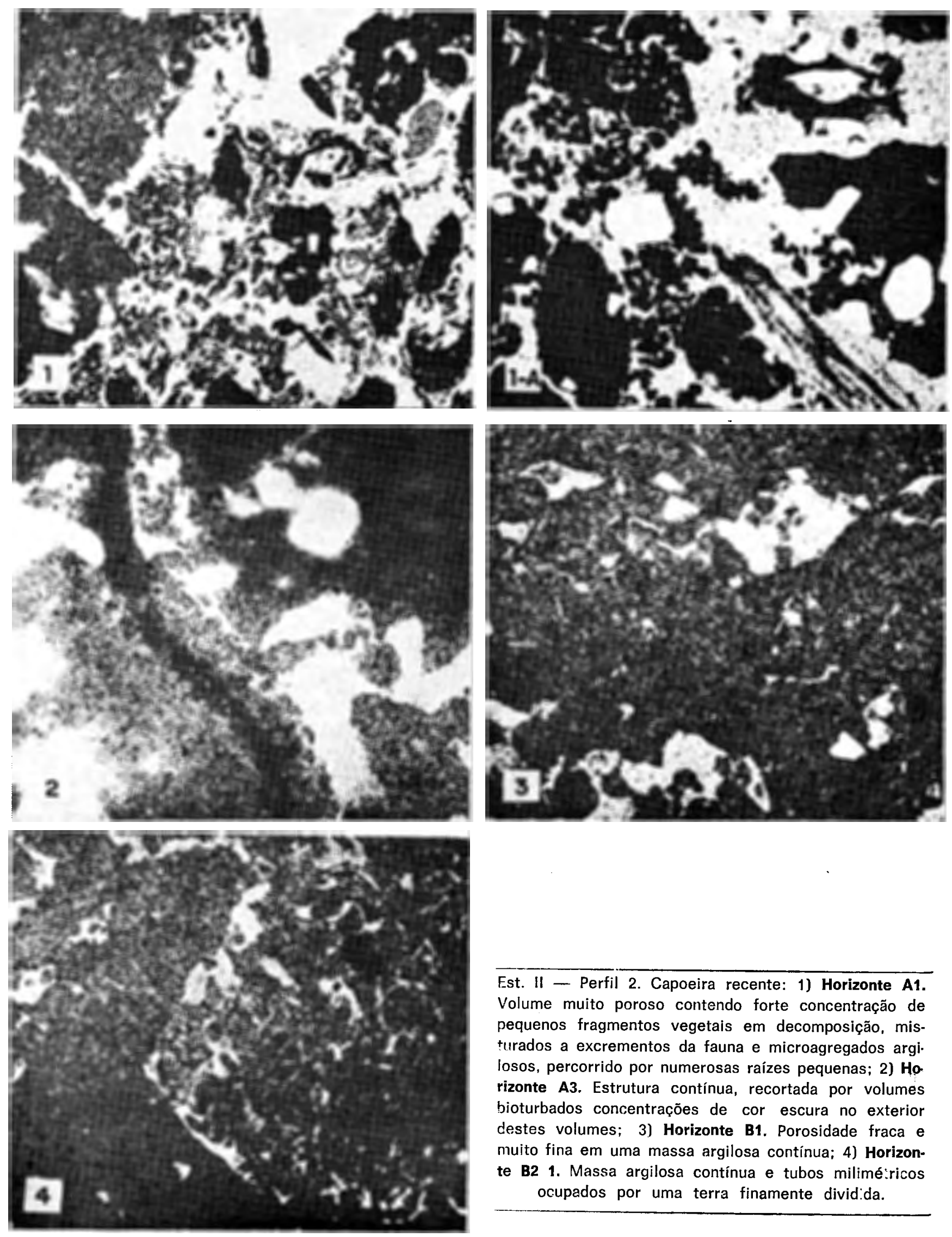

Est. II - Perfil 2. Capoeira recente: 1) Horizonte A1. Volume muito poroso contendo forte concentração de pequenos fragmentos vegetais em decomposição, misturados a excrementos da fauna e microagregados argj. losos, percorrido por numerosas raizes pequenas; 2) $\mathrm{Ho}$ rizonte A3. Estrutura contínua, recortada por volumes bioturbados concentraçōes de cor escura no exterior destes volumes; 3) Horizonte B1. Porosidade fraca e muito fina em uma massa argilosa contínua; 4) Horizonte B2 1. Massa argilosa contínua e tubos miliméiricos ocupados por uma terra finamente dividida. 
- O horizonte B22, enfim, é ainda bastante comparável ao observado no perfil de referência sob floresta primária, caracterizado pela presença de tubos, ocupados pela terra finamente dividida.

Várias constatações ressaltam destas ob. servações microscópicas:

1.\% Sob floresta primária parece existir um horizonte subsuperficial A3 (até $35 \mathrm{~cm}$ ) fracamente poroso, que opõe uma certa dificuldade à penetração das raízes.
2.\% Após desmatamento parcial e no decorrer da regeneração da floresta, uma intensa atividade biológica afeta os horizontes $A 1$ e $A 3$ (até $32 \mathrm{~cm}$ ), enquanto que o horizonte $B 1$ subjacente (de 32 a $60 \mathrm{~cm}$ ) apresenta um mínimo de porosidade e os horizontes B21 e B22 são pouco modificados.

$3 . \%$ o cultivo mecanizado parece afetar fortemente a microestrutura dos horizontes Ap e $A 3$ (até $33 \mathrm{~cm}$ ) cuja porosidade, re-
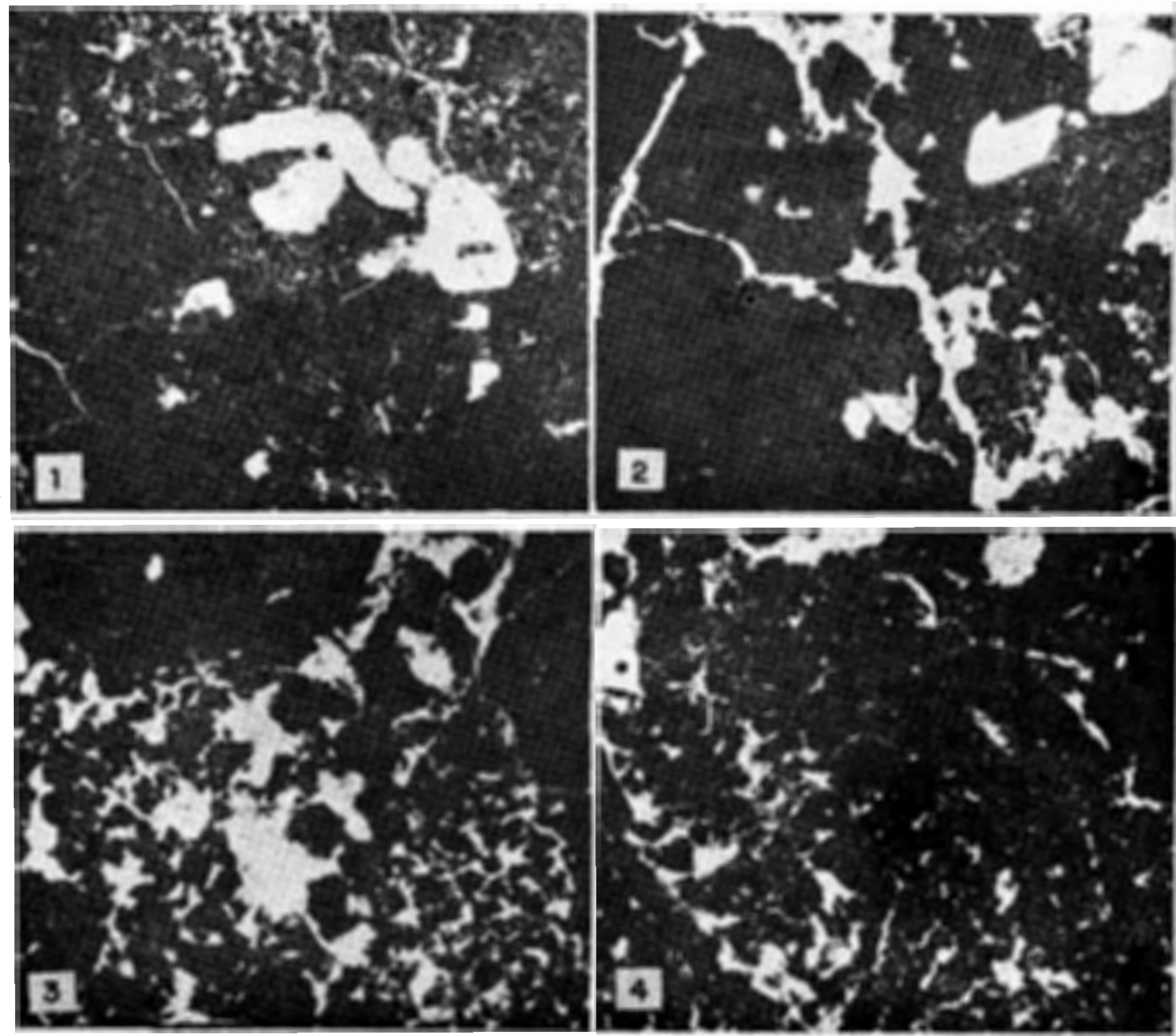

Est. III - Perfil 4. Cultura mecanizada: 1) Horizonte Ap. Plasma argiloso contínuo, recortado por fissuras muito finas e localmente, por alguns tubos; 2) Horizonte A3. Fissuras dispostas obliquamente; 3) Horizonte B2 1. Localmente e finamente dividido, percorrido por numerosos canais, de origem biológica, preenchidos por microagregados; 4) Horizonte B22. Tubos milimétricos ocupados por uma terra finamente dividida. 
duzida, é em grande parte fissural e portanto pouco favorável à permeabilidade (as fissuras tendem a se fechar quando o solo está úmido) e ao desenvolvimento das raízes (que recobrem as superfícies mas penetram pouco nos agregados). Os horizontes B21 e B22 guardam uma porosidade de origem biológica importante.

\section{AVALIAÇÃO DOS VOLUMES OCUPADOS} RESPECTIVAMENTE PELA MATÉRIA SÓLIDA, POR ÁGUA E POR AR.

Esta avaliação é feita a partir dos resultados das pesagens das amostras de $100 \mathrm{~cm}^{3}$, coletadas no estado úmido, 2 dias após uma forte chuva (no estado inicial, e depois de secagem na estufa a $105^{\circ}$ ).

Pode-se considerar, grosso-modo, que o volume então ocupado pela água corresponde sensivelmente ao da microporosidade apenas visível nas microfotos (diâmetro inferior a $30 \mu \mathrm{m}$, ou de $1 \mathrm{~mm}$ nas ampliações), enquanto que o ocupado pelo ar equivale à macroporosidade (vazios de $30 \mu \mathrm{m}$ e mais).

O conjunto dos resultados obtidos está representado graficamente na figura 1. Constata-se que estes dados confirmam e precisam, globalmente, as estimativas deduzidas da análise microscópica, colocando em evidência as variações entre os diferentes perfis estudados.
AVALIAÇÃO DOS TEORES VOLUMÉTRICOS EM MATÉRIA ORGÂNICA, NITROGÊNIO E FóSFORO NOS PERFIS PEDOLÓGICOS

Representamos graficamente na figura 2 as variações verticais destes teores, em uma profundidade de 1 metro, a partir da superfície do solo.

Nos 4 perfis, os teores em matérìa orgânica são da ordem de 40 a $50 \mathrm{~g}$ por $\mathrm{dm}^{3}$ nos horizontes $A 1$ ou $A p$ (ligeiramente superiores sob capoeira recente). Diminuem progressivamente para atingir valores compreendidos entre $10 \mathrm{~g} / \mathrm{dm}^{3}$ (floresta primária, capoeira antiga e plantação) e $15 \mathrm{~g} / \mathrm{dm}^{3}$ (capoeira recente) no horizonte B21. A penetração profunda da matéria orgânica nesses soios foi evidenciada por Voikoff \& Cerri (1981).

Constata-se uma certa analogia entre as distribuições de matéria orgânica nos perfis sob floresta primária e sob capoeira antiga: decrescimento rápido no horizonte $\mathrm{A} 1$ e topo do $A 3$, depois ligeiro aumento ao nível do $A 3$, e diminuição muito progressiva abaixo deles.

Ao inverso, o perfil sob capoeira recente se caracteriza por uma forte acumulação nos horizontes $A 1$ e $A 3$, e fracas variações abaixo.

O perfil estudado sob uma plantação jovem de Hevea enfim, se caracteriza por uma diminuição progressiva nos horizontes $\mathrm{A} 1 \mathrm{e}$ $A 3$, até ao topo do B21, depois por um teor quase constante em profundidade.
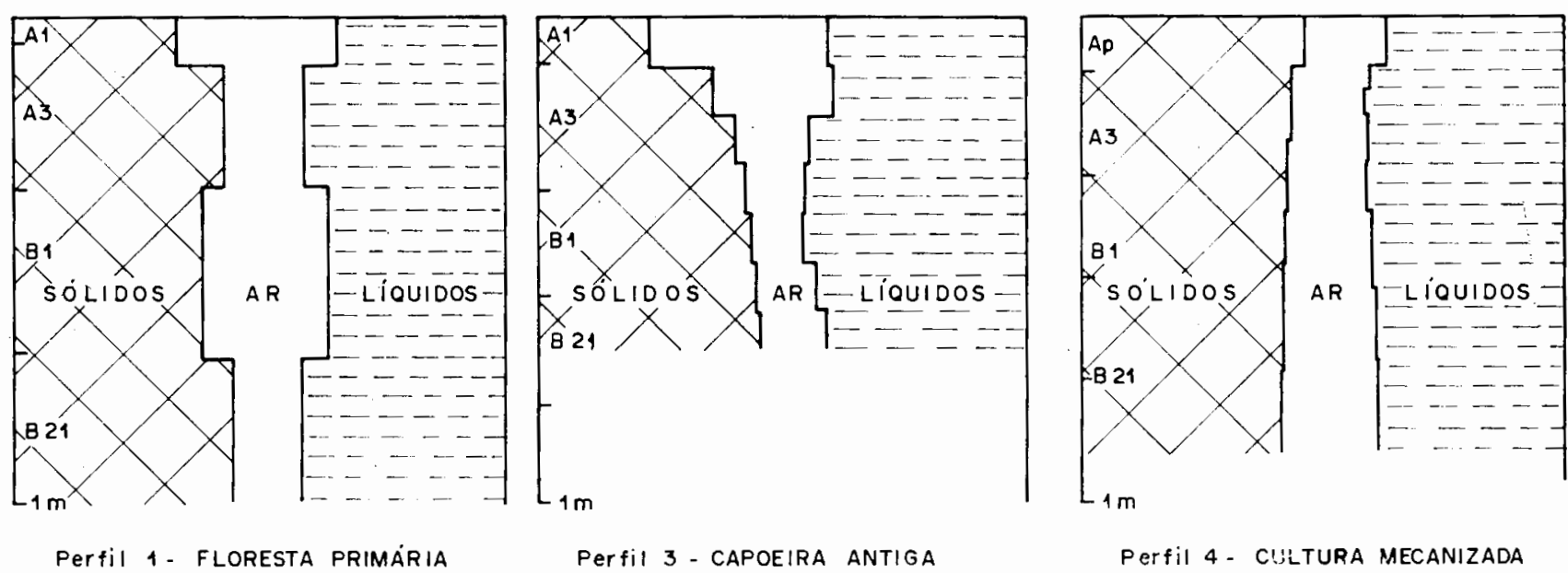

Perfil 4 - CULTURA MECANIZADA

Fig. 1 - Volumes ocupados respectivamente pela matéria sólida, por água e por ar, no estado úmido, 2 dias após uma chuva forte. 
No que concerne à distribuição do nitrogênio nos perfis, constata-se uma forte analogia com a matéria orgânica total (deduzida do carbono), salvo nos horizontes $A 1$, mais ou menos enriquecidos em matéria vegetal em vias de decomposição (podendo haver fragmentos de carvão de madeira). Este caracter é revelado pelas relações $\mathrm{C} / \mathrm{N}$, elevadas nos 2 perfis sob capoeira (16,4 e 16), mais fracas sob plantação de Hevea (14) e mínima sob floresta primária $(13,6)$.

No que concerne ao fósforo, enfim, observa-se uma relação com a distribuição da matéria orgânica, ainda que esta seja nitidamente menos marcada. Isto significa que a dinâmica do fósforo parece estar aqui ligada à da matéria orgânica. Os fortes teores encontrados sob plantação de Hevea são provavelmente devidos às adubações fosfatadas.

A AVALIAÇÃo DOS TEORES EM MATÉRIA ORGÂNICA, NITROGÊNIO, FÓSFORO, CÁLCIO, MAGNÉSIO E POTÁSSIO, CORRESPONDENTE A UMA

SUPERFÍCIE DE 1 HECTARE POR 1 METRO DE PROFUNDIDADE

Os resultados destas avaliações estão agrupados no quadro n. 2 .

A interpretação dos dados reunidos neste quadro pode ser feita em 3 níveis.

a) Por comparação entre os perfis estudados.

Constata-se de início que os resultados variam relativamente pouco de um perfil para outro. Isto significa que a unidade pedológica considerada los latossolos amarelos argilosos) é homogênea, o que não chega a ser surpreendente, levando-se em conta a uniformidade do material original no zona considerada e da floresta primária que, há algumas dezenas de anos atrás, recobria ainda todos estes solos.

Tendo em conta o número limitado de perfis estudados e de análises feitas, torna-se impossivel interpretar rigorosamente as pequenas diferenças encontradas. Entretanto, podemos constatar que os tratamentos aplicados à floresta primária modificaram relativamente pouco os teores em matéria orgânica e em nutrientes, inicialmente contidos no latossolo.

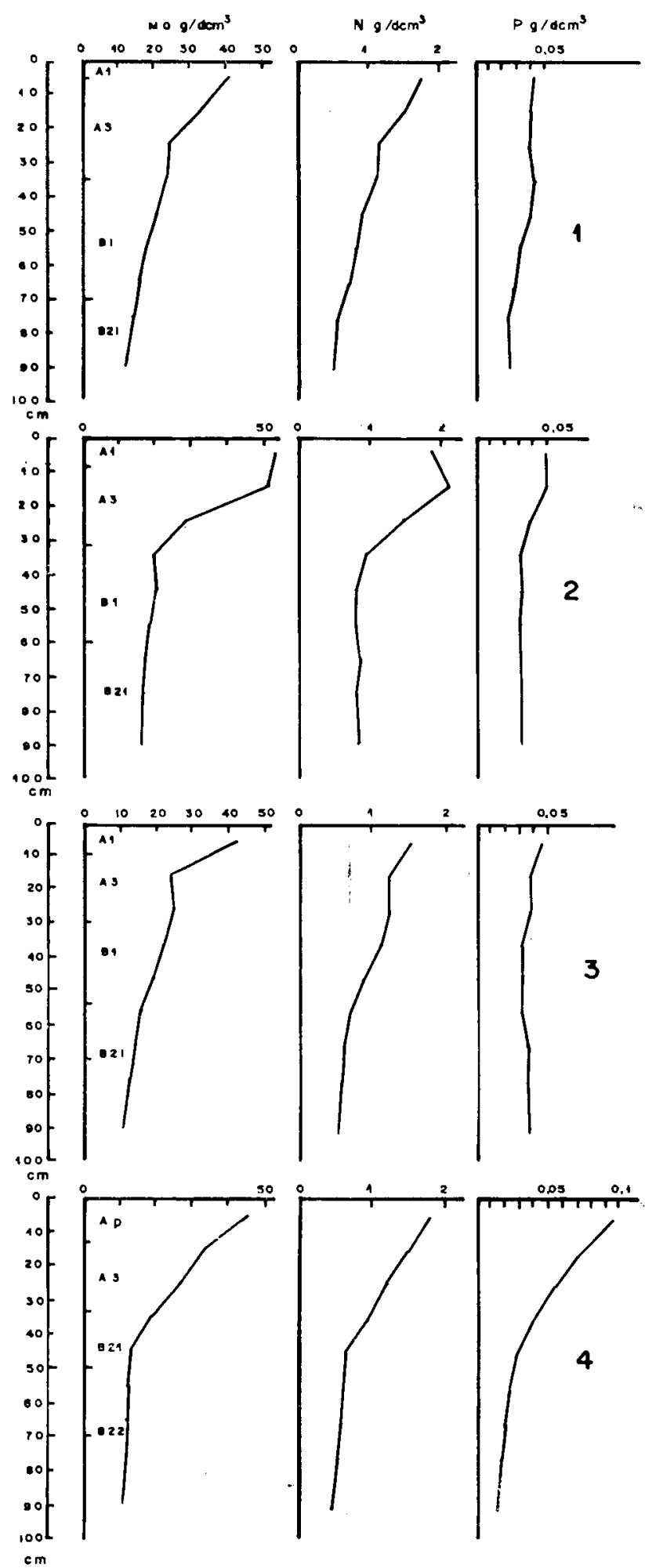

Fig. 2 - Variaçōes dos teores volúmicos em matéria orgânica (M.O.), Nitrogênio (N) e Fósforo (P), em profundidade, por perfis de referência sob floresta primária (1) - capoeira recente (2) - capoeira antiga (3) e plantação (4). 
QUADRO 2 - Teores em matéria orgânica e nutrientes correspondentes a 1 ha. por 1 metro de profundidade.

\begin{tabular}{|c|c|c|c|c|c|}
\hline & & $\begin{array}{l}\text { Perfil } 1 \\
\text { (de preferência) } \\
\text { Floresta primária }\end{array}$ & $\begin{array}{l}\text { Perfil } 2 \\
\text { Capoeira } \\
\text { recente }\end{array}$ & $\begin{array}{l}\text { Perfil } 3 \\
\text { Capoeira } \\
\text { antiga }\end{array}$ & $\begin{array}{c}\text { Perfil } 4 \\
\text { Plantação }\end{array}$ \\
\hline Matéria orgânica & & $210 \mathrm{t} / \mathrm{ha}$ & $250 \mathrm{t} / \mathrm{ha}$ & $190 \mathrm{t} / \mathrm{ha}$ & $191 \mathrm{t} / \mathrm{ha}$ \\
\hline Nitrogênio* & & $9 \mathrm{t} / \mathrm{ha}$ & $10,6 \mathrm{t} / \mathrm{ha}$ & $8,7 \mathrm{t} / \mathrm{ha}$ & $8,5 \mathrm{t} / \mathrm{ha}$ \\
\hline Nitrogênio ${ }^{*}$ & $\begin{array}{l}\text { assimilável } \\
\text { total }\end{array}$ & $\begin{array}{r}17 \mathrm{~kg} / \mathrm{ha} \\
327 \mathrm{~kg} / \mathrm{ha}\end{array}$ & $340 \mathrm{~kg} / \mathrm{ha}$ & $\begin{array}{r}14 \mathrm{~kg} / \mathrm{ha} \\
333 \mathrm{~kg} / \mathrm{ha}\end{array}$ & $\begin{array}{r}33 \mathrm{~kg} / \mathrm{ha} \\
364 \mathrm{~kg} / \mathrm{ha}\end{array}$ \\
\hline $\begin{array}{l}\text { Bases } \\
\text { trocáveis" }\end{array}$ & $\begin{array}{l}\mathrm{Ca}++ \\
\mathrm{Mg}++ \\
\mathrm{K}++\end{array}$ & $\begin{array}{r}383 \mathrm{~kg} / \mathrm{ha} \\
82 \mathrm{~kg} / \mathrm{ha} \\
58 \mathrm{~kg} / \mathrm{ha}\end{array}$ & - & $\begin{array}{r}450 \mathrm{~kg} / \mathrm{ha} \\
84 \mathrm{~kg} / \mathrm{ha} \\
34 \mathrm{~kg} / \mathrm{ha}\end{array}$ & $\begin{array}{r}366 \mathrm{~kg} / \mathrm{ha} \\
107 \mathrm{~kg} / \mathrm{ha} \\
86 \mathrm{~kg} / \mathrm{ha}\end{array}$ \\
\hline $\begin{array}{l}\text { Bases } \\
\text { "totais" }\end{array}$ & $\begin{array}{l}\mathrm{Ca} \\
\mathrm{Mg} \\
\mathrm{K}\end{array}$ & $\begin{array}{l}9,6 \mathrm{t} / \mathrm{ha} \\
1,3 \mathrm{t} / \mathrm{ha} \\
1,5 \mathrm{t} / \mathrm{ha}\end{array}$ & $\begin{array}{l}9,2 \mathrm{t} / \mathrm{ha} \\
1,3 \mathrm{t} / \mathrm{ha} \\
1,5 \mathrm{t} / \mathrm{ha}\end{array}$ & $\begin{array}{l}8,9 \mathrm{t} / \mathrm{ha} \\
1,3 \mathrm{t} / \mathrm{ha} \\
1,5 \mathrm{t} / \mathrm{ha}\end{array}$ & $\begin{array}{l}8,9 \mathrm{t} / \mathrm{ha} \\
1,3 \mathrm{t} / \mathrm{ha} \\
1,5 \mathrm{t} / \mathrm{ha}\end{array}$ \\
\hline
\end{tabular}

(*) - Esses resultados são da mesma ordem de grandeza que os de Klinge (19;'̌) para o nitrogènio e o potássio (trocável): são superiores para o fósforo e sobretudo para o magnésio e o cálcio trocóvel.

A relativa constância destes dados tem sua significação reforçada através da comparação com outros dados relativos ao ecossistema estudado.

b) Por comparação com os dados relativos à biomassa.

Não dispomos de dados analíticos sobre a biomassa da região estudada. Pode-se, entretanto, considerar que os resuldatos citados na bibliografia para outras florestas tropicais de baixa altitude, fornecem uma primeira aproximação válida. Consideramos aqui os valores dados por Golley et al. (1969) para a floresta do Panamá, por Ovington \& Olson (1970) para Porto Rico e por Bernhard-Reversat (1975) para a Costa do Marfim (floresta de Yapo).

Reagrupamos no quadro 3 , os valores que obtivemos com relação ao solo, e aos encontrados na bibliografia para a biomassa.

Ainda que a confrontação entre estes dados que correspondem a ecossistemas diferentes seja criticável, pode-se entretanto deduzir validamente algumas indicações gerais.

Parece assim que a ordem de grandeza das quantidades de matéria orgânica contidas no solo, em um metro de profundidade; não difere muito das da biomassa. Um estudo do ciclo do carbono no ecossistema deverá, portanto, levar em conta as quantidades importantes de matéria orgânica contidas e recicladas nos solos.

Quanto ao nitrogênio, parece que as quantidades contidas nos solos são quase 10 vezes mais importantes que as contidas na biomassa.

Para o fósforo, constata-se que se for apenas considerada a fração "assimilável Olsen" (cuja distribuição no solo parece estar mals ou menos ligada à da matéria orgânica e. portanto, dependente da atividade biológica), está é bem inferior a imobilizada na biomassa; enquanto que o fósforo total está muito mais representado no solo que na biomassa.

Para as bases ( $\mathrm{Ca}, \mathrm{Mg}$ e $\mathrm{K}$ ), constata-se da mesma maneira, que as quantidades ditas "trocáveis" são nitidamente inferiores às irinobilizadas na biomassa, mas as quantidades "totais", são ao contrário, muito mais elevadas.

O problema é, portanto, saber sob que formas estão retidas nos solos as formas "não assimiláveis" do fósforo, e "não trocáveis" 
QUADRO 3 - Quantidades de matéria orgânica e de nutrientes no solo e na biomassa.

\begin{tabular}{|c|c|c|c|c|c|c|c|c|c|c|c|}
\hline & & \multirow{2}{*}{$\begin{array}{l}\text { Matéria } \\
\text { orgânica }\end{array}$} & \multirow{2}{*}{$\begin{array}{c}\text { Nitrogê- } \\
\text { nio }\end{array}$} & \multicolumn{2}{|c|}{ Fósforo } & \multicolumn{2}{|c|}{ Cálcio } & \multicolumn{2}{|c|}{ Magnésio } & \multicolumn{2}{|c|}{ Potássio } \\
\hline & & & & Assimilado & Total & Trocável & Total & Trocável & Total & Trocável & Total \\
\hline \multicolumn{2}{|c|}{$\begin{array}{l}\text { Solo } \\
\text { da Bacia }\end{array}$} & $\begin{array}{l}190 \\
\text { à } \\
250 \mathrm{t} / \mathrm{ha}\end{array}$ & $\begin{array}{c}8,5 \\
\text { a } \\
10,6 \text { t/ha }\end{array}$ & $\begin{array}{l}14 \\
\text { à } \\
17 \mathrm{~kg} / \mathrm{ha}\end{array}$ & $\begin{array}{l}327 \\
\text { à } \\
340 \mathrm{~kg} / \mathrm{ha}\end{array}$ & $\begin{array}{l}336 \\
\mathrm{a} \\
450 \mathrm{~kg} / \mathrm{ha}\end{array}$ & $\begin{array}{l}8,9 \\
\text { à } \\
9,6 \text { t/ha }\end{array}$ & $\begin{array}{l}82 \\
\text { a } \\
107 \mathrm{~kg} / \mathrm{ha}\end{array}$ & $1,3 \mathrm{t} / \mathrm{ha}$ & $\begin{array}{l}34 \\
\text { à } \\
58 \mathrm{~kg} / \mathrm{ha}\end{array}$ & $1,5 \mathrm{t} / \mathrm{ha}$ \\
\hline \multirow[t]{2}{*}{ 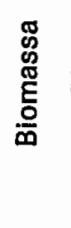 } & $\begin{array}{l}\text { Panamá } \\
\text { Porto Rico } \\
\text { Costa do }\end{array}$ & $\begin{array}{l}276 \mathrm{t} / \mathrm{ha} \\
200 \mathrm{t} / \mathrm{ha}\end{array}$ & $\begin{array}{l}- \\
0,814 \mathrm{t} / \mathrm{ha}\end{array}$ & \multicolumn{2}{|c|}{$\begin{array}{l}33 \mathrm{~kg} / \mathrm{ha} \\
43 \mathrm{~kg} / \mathrm{ha}\end{array}$} & \multicolumn{2}{|c|}{$875 \mathrm{~kg} / \mathrm{ha}$} & \multicolumn{2}{|c|}{$376 \mathrm{~kg} / \mathrm{ha}$} & \multicolumn{2}{|c|}{$1045 \mathrm{~kg} / \mathrm{ha}$} \\
\hline & Marfim & $330 \mathrm{t} / \mathrm{ha}$ & $0,850 \mathrm{t} / \mathrm{ha}$ & \multicolumn{2}{|c|}{$70 \mathrm{~kg} / \mathrm{ha}$} & 1660 & /ha & \multicolumn{2}{|c|}{$170 \mathrm{~kg} / \mathrm{ha}$} & \multicolumn{2}{|c|}{$350 \mathrm{~kg} / \mathrm{ha}$} \\
\hline
\end{tabular}


QUADRO 4 - Estimativas das reservas em nitrogênio, fósforo e bases trocáveis, no latossolo argiloso da estação INPA e em 2 solos da Costa do Marfim sob floresta subequatorial.

\begin{tabular}{|c|c|c|c|c|c|}
\hline & Nitrogênio & $\begin{array}{c}\text { Fósforo } \\
\text { total }\end{array}$ & Cálcio & $\begin{array}{l}\text { Magnésio } \\
\text { Macáveis }\end{array}$ & Potássio \\
\hline \multirow[t]{2}{*}{ Latossolo argiloso } & 6,4 & 174 & 180 & 44 & 20 \\
\hline & $\mathbf{a}$ & $\mathbf{a}$ & a & a & $\mathbf{a}$ \\
\hline Estação INPA & $6,9 \mathrm{t} / \mathrm{ha}$ & $280 \mathrm{~kg} / \mathrm{m}$ & $353 \mathrm{~kg} / \mathrm{ha}$ & $70 \mathrm{~kg} / \mathrm{ha}$ & $48 \mathrm{~kg} / \mathrm{ha}$ \\
\hline \multicolumn{6}{|l|}{ "Banco" Platô } \\
\hline Costa do Marfim & $4,8 \mathrm{t} / \mathrm{ha}$ & $680 \mathrm{~kg} / \mathrm{ha}$ & $97 \mathrm{~kg} / \mathrm{ha}$ & $82 \mathrm{~kg} / \mathrm{ha}$ & $83 \mathrm{~kg} / \mathrm{ha}$ \\
\hline \multicolumn{6}{|l|}{ "Banco" talvegue } \\
\hline Costa do Marfim & $4,6 \mathrm{t} / \mathrm{ha}$ & $1300 \mathrm{~kg} / \mathrm{ha}$ & $200 \mathrm{~kg} / \mathrm{ha}$ & $106 \mathrm{~kg} / \mathrm{ha}$ & $157 \mathrm{~kg} / \mathrm{ha}$ \\
\hline
\end{tabular}

das bases. Como todos os minerais primários susceptíveis de conter estes elementos estão ausentes, parece que estes se encontram retidos em locais pouco acessíveis, ou sob "formas transitórias" mal conhecidas (Masozera \& Bouyes, 1972).

O importante é saber em que medida os elementos assim retidos, participam dos ciclos biológicos, no interior dos ecossistemas.

c) Comparação com os solos dos outros ecossistemas florestais tropicais.

Esta comparação pode ser feita com 2 solos da Costa do Marfim, situados sob floresta primária, e estudados pelos mesmos métodos por Bernhard-Reversat, mas somente até 0.5 $\mathrm{m}$ de profundidade. Consideraremos portanto a mesma profundidade.

A comparação só poderá ser feita com os elementos citados por Bernhard-Reversat, a saber o nitrogênio, fósforo total e bases trocáveis.

Constata-se que os teores em nitrogênio e em cálcio trocável dos solos estudados na estação do INPA, são um pouco superiores aos dos solos do Banco na Costa do Miarfim, enquanto que os teores em fósforo total e em magnésio e potássio trocáveis são nitidamente inferiores.

\section{Conclusões gerais}

Três conclusões principais ressaitam deste trabalho.

A primeira à propósito da adaptação dos métodos da pedologia aos estudos interdisciplinares de ecologia, tal como aquele desenvolvido pelo INPA. Parece necessário que os conhecimentos adquiridos em todos os domínios possam ser situados em relação à própria estrutura do ecossistema, considerado em todo o seu conjunto. Dever-se-a, portanto, proceder à análise estrutural da própria cobertura pedológica. Dever-se-á também exprimir os dados de laboratório em função dos volumes e das superfícies que caracterizam esta estrutura, assim como todas as outras características do meio.

A segunda conclusão é sobre a importância preponderante das transformações estruturais (comparadas às modificações químicas) na evolução dos ecossistemas florestais, após uma intervenção humana. Constatamos, assim, que as variações mais importantes dizem respeito à porosidade dos solos; e são elas precisamente que determinam os movimentos dos fluídos e dos organismos vivos e, portanto, a dinâmica dos sistemas.

A terceira conclusão, enfim, é a necessidade de se ter $\mathrm{em}$ conta, no estudo dos ciclos 
de nutrientes, não apenas as frações "assimiláveis" e "trocáveis", que são a mais diretamente disponíveis, e que representam perto de 5 a $10 \%$ dos teores efetivamente contidos nos solos (na mesma proporção que as partes emersas dos "icebergs"). Parece muito importante estudar sob que formas se encontram os elementos totais e qual pode ser a sua participação nos ciclos biológicos.

\section{SUMMARY}

A pedological study of the most common "latossolos amarelos, alicos, argilosos" (heavy yellow clay latossols) was made on the plateau of the ZF 2 region.

The "initial reference state" under the primary forest is characterized by the presence of a medium horizon that is porous and contains strong micro-agregates between two less porous horizons. This soil is also characterized by a uniform and deeply distributed organic matter content.

Soil under young secondary regrowth showed a different distribution of pores and organic matter. However with time, these evolve towards the former situation under the initial forest.

Mechanically cultivated soils have a low porosity in the surface and progressively less organic matter down to $45 \mathrm{~cm}$.

\section{REFERENCIAS BIBLIOGRAFICAS}

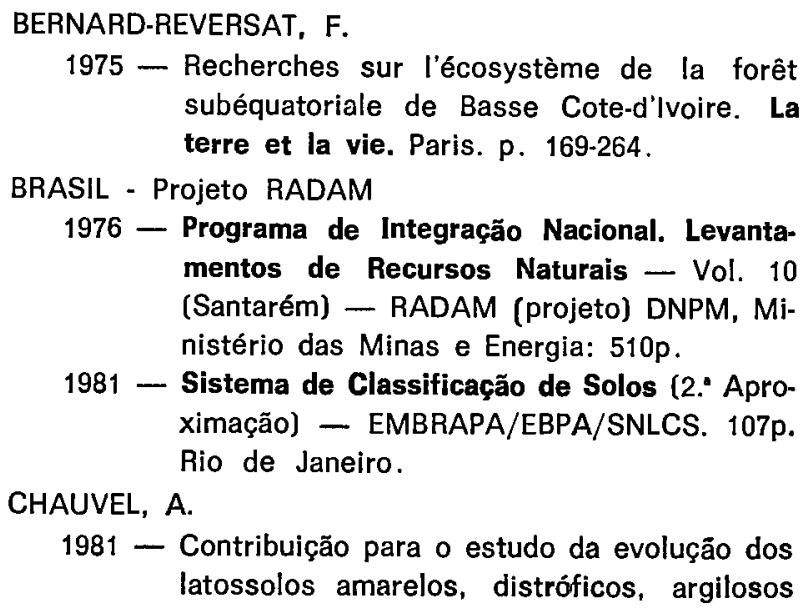
subéquatoriale de Basse Cote-d'Ivoire. La terre et la vie. Paris. p. 169-264.

BRASIL - Projeto RADAM

1976 - Programa de Integração Nacional. Levantamentos de Recursos Naturais - Vol. 10 (Santarém) - RADAM (projeto) DNPM, Ministério das Minas e Energia: 510p.

1981 - Sistema de Classificação de Solos (2: Aproximação) - EMBRAPA/EBPA/SNLCS. 107p. Rio de Janeiro.

CHAUVEL, A.

1981 - Contribuição para o estudo da evolução dos latossolos amarelos, distróficos, argilosos

na borda do platô, na região de Manaus: mecanismos da gibbsitização. Acta Amazonica, 11 (2): 227-245.

CPCS (Commission de Pédologie et de Cartographie des Sols]

1967 - Classification française Document provisoire de I'Ecole. Nat. Sup. Agron. GRIGNON. 87p.'

GOLLEY, F.B.; MAC GINNIS, J.T.; CLEMENTS, R.G.;

CHILD, G.I.; DUEVER, M.J.

1969 - The structure of tropical forest in Panama and Colombia. Bio-Science, 19: 693-696.

FALESI, I.C. et al.

1969 - Os Solos da área Manaus-ltacoatiara. IPEAN. Secretaria de Produção do Estado do Amazonas (Estudo e ensaios, 1). Rio de Janeiro: $116 \mathrm{p}$.

KLINGE, $H$.

1975 - Bilanzierung von Hauptnährstoffen im Oek()system tropischer Regenwald (Manaus) Vorläufige Daten. Biogeographica, 7: 59-99.

MASOZERA, C. \& BOUYE, S.S.

1972 - Potassium et calcium labiles dans quelques types de sols tropicaux. Coll. FAO/IAEA. Vienne.

OVINGTON, J.D. \& OLSON, J.S.

1970 - Biomass and chemical content of El Verd lower montane rain forest plants. In: A tropical rain forest, ODUM, H.T. ed., Div. Techn. Inform. US Atom. Energy Comission $\mathrm{H} .2, \mathrm{H} 53-\mathrm{H} 77$.

RANZANI, G.

1980 - Identificação e caracterização de alguns solos da Estação Experimental de Silvicultura Tropical do INPA. Acta Amazonica, 10 (1): 7-41.

SOIL SURVEY STAFF

1975 - Soil taxonomy, a basic system of Soil. Classification for making and interpreting Soil Survey. USDA, AGR. HANDB. 436-U.S. Government Printing Office. Washington D.C.

VILLA NOVA, N.A.; SALATI, E.; MATSUI, E. 1976 - Estimativa da evapotranspiração na Bacia Amazônica. Acta Amazonica, 6 (2): 215-228.

VOLKOFF, B. \& CERRI, C.C. 1981 - Humus da floresta Amazônica na região do rio Madeira. R. Bras. Ci. Solo, 5 (1): 15-21.

(Aceito para publicação em 14/05/82) 
QUADRO $1-$ Caracteristicas analiticas dos solos estudados: a $=$ argila; s.t. $=$ silto fino; s.g. $=$ silto grosso; a.f $=$ areia fina; a.g. $=$ areia grosse

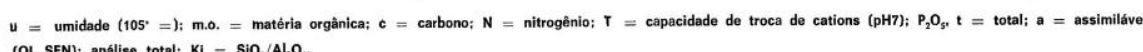

\begin{tabular}{|c|c|c|c|c|c|c|c|c|c|c|c|c|c|c|c|c|c|c|c|c|c|c|c|c|c|c|c|c|}
\hline \multirow{2}{*}{$\begin{array}{l}\text { Perfis } \\
\text { Horizonte }\end{array}$} & \multirow{2}{*}{$\begin{array}{l}\text { Prof. } \\
\mathrm{cm} .\end{array}$} & \multicolumn{6}{|c|}{ Granulometria \% } & \multirow{2}{*}{$\begin{array}{l}\text { M.o. } \\
\%\end{array}$} & \multirow{2}{*}{$\begin{array}{c}c . \\
\% \\
\%\end{array}$} & \multirow{2}{*}{$\%$} & \multirow{2}{*}{$\mathrm{C} / \mathrm{N}$} & \multirow{2}{*}{$\frac{{ }^{\mathrm{pH}}}{\mathrm{H}_{2} \mathrm{O} \quad \mathrm{HCl}}$} & \multicolumn{5}{|c|}{$\begin{array}{c}\text { Bases trocavels } \\
\text { me } / 100 \mathrm{~g}\end{array}$} & \multirow{2}{*}{$T$} & \multirow{2}{*}{ 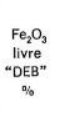 } & \multicolumn{2}{|c|}{ P2 $05 \%$} & \multicolumn{7}{|c|}{ Analise Total $\%$} \\
\hline & & a & s.f & 8.9 & a.f & ag & u & & & & & & $\mathrm{Ca}^{++}$ & ${ }_{++}^{\mathrm{Mg}}$ & ${ }^{k}+$ & $\mathrm{Na}^{+}$ & $\mathrm{s}$ & & & $t$ & a & $\mathrm{Fe}_{2} \mathrm{O}_{3}$ & $\mathrm{TiO}_{2}$ & cao & $\mathrm{MgG}_{\mathrm{g}}$ & $\mathrm{K}_{2} \mathrm{O}$ & $\mathrm{Na}_{2} \mathrm{O}$ & Ki \\
\hline 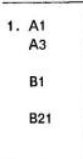 & $\begin{array}{r}0-10 \\
10=20 \\
20=30 \\
30=40 \\
50=60 \\
80=90 \\
120-140\end{array}$ & $\begin{array}{l}80.5 \\
83.0 \\
84,2 \\
84.5 \\
87,5 \\
89.0 \\
89.1\end{array}$ & $\begin{array}{l}1.0 \\
1.1 \\
1,1 \\
1,0 \\
1,6 \\
1.0 \\
1.6\end{array}$ & $\begin{array}{l}0,3 \\
0.3 \\
0,2 \\
0,2 \\
0.2 \\
0.2 \\
0,5\end{array}$ & $\begin{array}{l}3.8 \\
4,2 \\
4,2 \\
3,8 \\
3,1 \\
2,6 \\
2,7\end{array}$ & $\begin{array}{l}7.3 \\
6.3 \\
6,3 \\
6.8 \\
4,2 \\
4,7 \\
3,9\end{array}$ & $\begin{array}{l}2.1 \\
1,9 \\
1,8 \\
1,7 \\
1,7 \\
1,5 \\
1,5\end{array}$ & $\begin{array}{l}5,0 \\
3,2 \\
2,2 \\
2,0 \\
1,7 \\
1,0 \\
0.7\end{array}$ & $\begin{array}{c}28,8 \\
18,7 \\
12,8 \\
11,7 \\
9.65 \\
5.69 \\
4,28\end{array}$ & $\begin{array}{l}2,12 \\
1,48 \\
1.02 \\
0.938 \\
0,794 \\
0 ., 499 \\
0.344\end{array}$ & $\begin{array}{l}13,6 \\
12,6 \\
12.5 \\
12.5 \\
12,2 \\
11.6 \\
12,4\end{array}$ & $\begin{array}{ll}4,3 & 3.6 \\
4,3 & 3.7 \\
4,6 & 3.8 \\
4.7 & 3.9 \\
4,9 & 3.9 \\
5.5 & 4.1 \\
5,3 & 4.2\end{array}$ & $\begin{array}{l}0.24 \\
0.24 \\
0.24 \\
0.218 \\
0.18 \\
0.12 \\
0.12\end{array}$ & $\begin{array}{l}0.12 \\
0.06 \\
0.06 \\
0.06 \\
0.18 \\
0.06 \\
0.06 \\
0.06\end{array}$ & $\begin{array}{l}0.05 \\
0.03 \\
0,02 \\
0.01 \\
0.06 \\
0.01 \\
0.01 \\
0.01\end{array}$ & $\begin{array}{l}0.06 \\
0.02 \\
0.02 \\
0.02 \\
0.02 \\
0.01 \\
0.02 \\
0.02\end{array}$ & $\begin{array}{l}0.47 \\
0.35 \\
0.34 \\
0.27 \\
0.26 \\
0.21 \\
0.21\end{array}$ & $\begin{array}{l}10,5 \\
7.0 \\
5.0 \\
5,5 \\
4.5 \\
2.5 \\
2.0\end{array}$ & $\begin{array}{l}1.4 \\
1.4 \\
1.45\end{array}$ & $\begin{array}{l}0.120 \\
0.090 \\
0.0800 \\
0.0800 \\
0.070 \\
0.0945 \\
0.045\end{array}$ & $\begin{array}{c}0.015 \\
0.013 \\
0.006 \\
0.003 \\
0 \\
0 \\
0\end{array}$ & $\begin{array}{l}3,40 \\
3,40 \\
3,60\end{array}$ & $\begin{array}{l}2.65 \\
2.80 \\
2.87\end{array}$ & $\begin{array}{l}0,14 \\
0,15 \\
0.12\end{array}$ & $\begin{array}{l}0,02 \\
0.02 \\
0,02\end{array}$ & $\begin{array}{l}0,02 \\
0.02 \\
0,02\end{array}$ & $\begin{array}{l}0.12 \\
0.12 \\
0.12\end{array}$ & $\begin{array}{l}1.64 \\
1.63 \\
1,66\end{array}$ \\
\hline $\begin{array}{l}\text { 2. A1 } \\
\text { A3 }\end{array}$ & $\begin{array}{r}0-\begin{array}{l}13 \\
15-25\end{array} \\
20\end{array}$ & $\begin{array}{l}75,2 \\
83,3\end{array}$ & $\begin{array}{l}1.1 \\
1.1\end{array}$ & $\begin{array}{l}0.2 \\
0.2\end{array}$ & $\begin{array}{l}4.3 \\
3.7\end{array}$ & $\begin{array}{l}7.8 \\
6.4\end{array}$ & $\begin{array}{l}2,7 \\
1.8\end{array}$ & $\begin{array}{l}8,7 \\
3.5\end{array}$ & $\begin{array}{l}50,4 \\
20,3\end{array}$ & & $\begin{array}{l}16,4 \\
14.0\end{array}$ & $\begin{array}{l}4,03.2 \\
4,1,1,6\end{array}$ & & & $\begin{array}{l}0.09 \\
0.04 \\
0.02\end{array}$ & & $\begin{array}{l}0.71 \\
0.42 \\
0.40\end{array}$ & $\begin{array}{r}19.0 \\
7,0 \\
4.0\end{array}$ & $\begin{array}{l}1.10 \\
1.20\end{array}$ & $\begin{array}{l}0,880 \\
0.090 \\
0,060\end{array}$ & $\begin{array}{l}0,017 \\
0,011\end{array}$ & $\begin{array}{l}2,40 \\
2,60\end{array}$ & $\begin{array}{l}1,95 \\
2,10\end{array}$ & $\begin{array}{l}0,12 \\
0,14\end{array}$ & $\begin{array}{l}0.02 \\
0,02\end{array}$ & $\begin{array}{l}0,02 \\
0,02\end{array}$ & $\begin{array}{l}0.110 \\
0.15\end{array}$ & $\begin{array}{l}1,68 \\
1,69\end{array}$ \\
\hline${ }_{B 1}$ & $\begin{array}{l}30 \\
40\end{array}$ & $\begin{array}{l}87,4 \\
86,1\end{array}$ & $\begin{array}{l}1,1, \\
2,6\end{array}$ & & & $\begin{array}{l}5 \\
4 \\
4\end{array}$ & & $\begin{array}{l}1.7 \\
1.7\end{array}$ & $\begin{array}{l}10.1 \\
{ }_{9.66}\end{array}$ & & $\begin{array}{l}12.4 \\
14,5\end{array}$ & 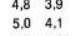 & $\begin{array}{l}0.24 \\
0.18\end{array}$ & $\begin{array}{l}0,06 \\
0.06\end{array}$ & 0,010 & & 0.27 & 3,5 & 1,20 & $\begin{array}{l}0.070 \\
0.0770 \\
0.706\end{array}$ & 0 & 2.70 & 2,12 & 0.12 & 0.02 & 0,02 & 0.15 & 1,67 \\
\hline B21 & $\begin{array}{l}60-70 \\
80-90 \\
100-110\end{array}$ & $\begin{array}{l}88.5 \\
88.3 \\
88.5\end{array}$ & $\begin{array}{l}1,1 \\
1,0 \\
1,0\end{array}$ & & $\begin{array}{l}2,6 \\
3.1 \\
3.1\end{array}$ & $\begin{array}{l}4.7 \\
4.4 \\
4.6\end{array}$ & $\begin{array}{l}1,4 \\
1,4 \\
1,4\end{array}$ & $\begin{array}{l}1,5 \\
1,4 \\
1,0\end{array}$ & $\begin{array}{l}8.79 \\
7.86 \\
5.91\end{array}$ & & $\begin{array}{l}12,4 \\
12,3 \\
11.7\end{array}$ & $\begin{array}{l}5.24 .2 \\
5.2 \\
5.2 \\
5.2 \\
.2\end{array}$ & & & $\begin{array}{l}0.01 \\
0.01 \\
0.01\end{array}$ & & $\begin{array}{l}0.21 \\
0.21 \\
0.21\end{array}$ & $\begin{array}{l}3.5 \\
3.0 \\
2.5\end{array}$ & & & $\begin{array}{l}0 \\
0 \\
0\end{array}$ & & & & & & & \\
\hline 3. $A_{1}$ & $0-3$ & 54.8 & 13.7 & 1,1 & 4,3 & 8.2 & 4,0 & 13.9 & 80.9 & 5.06 & 16.0 & $\begin{array}{l}4.9 \\
4.98 \\
43\end{array}$ & $\begin{array}{l}4.5 \\
0,78\end{array}$ & $\begin{array}{l}0.78 \\
0.24\end{array}$ & $\begin{array}{l}0.08 \\
0,03\end{array}$ & $\begin{array}{l}0.04 \\
0.02\end{array}$ & $\begin{array}{l}5,40 \\
0,77\end{array}$ & $\begin{array}{r}26.5 \\
9.0\end{array}$ & 1.75 & $\begin{array}{l}0.220 \\
0.12\end{array}$ & $\begin{array}{l}0.028 \\
0.004\end{array}$ & 4,50 & 2.72 & 0.12 & 0.02 & 0.02 & 0,18 & 1.84 \\
\hline $\mathrm{A}_{3}$ & $\begin{array}{l}3 \\
10\end{array}$ & $\begin{array}{l}818,6 \\
85,1\end{array}$ & $\begin{array}{l}1,0 \\
1,0\end{array}$ & & & $\begin{array}{l}7 \\
6\end{array}$ & . & $\begin{array}{l}3,5 \\
2,5\end{array}$ & & & $\begin{array}{l}12,3 \\
10.9\end{array}$ & $\begin{array}{l}4,3 \\
4,5 \\
3\end{array}$ & & $\begin{array}{l}0.12 \\
0.12\end{array}$ & $\begin{array}{l}0,0 \\
0.0\end{array}$ & 0. & & $\begin{array}{l}6,0 \\
4,5\end{array}$ & & & $\begin{array}{l}0.008 \\
0.033\end{array}$ & 5.00 & & 0,11 & 0.02 & 0.02 & 0.14 & 188 \\
\hline B1 & $\begin{array}{r}-45 \\
-70\end{array}$ & $\begin{array}{l}90,4 \\
909\end{array}$ & $\begin{array}{l}0.5 \\
1.0\end{array}$ & $\begin{array}{l}0.2 \\
0.2\end{array}$ & & $\begin{array}{l}3.2 \\
2.8\end{array}$ & 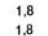 & $\begin{array}{l}1,8 \\
1,2\end{array}$ & $\begin{array}{l}10.2 \\
7.01\end{array}$ & & $\begin{array}{l}11,3 \\
11,7\end{array}$ & $\begin{array}{l}4,8 \\
5,1\end{array}$ & & $\begin{array}{l}0.1 \\
0.0\end{array}$ & $\begin{array}{l}0.01 \\
0.01\end{array}$ & $\begin{array}{l}0.6 \\
0.4\end{array}$ & & $\begin{array}{l}4,0 \\
4,0 \\
4,0\end{array}$ & $\begin{array}{l}1,90 \\
1,90\end{array}$ & 0.0600 & 0 & $\begin{array}{l}3.00 \\
5,00\end{array}$ & 2.99 & 0,12 & 0.02 & 0.02 & 0,17 & 1.85 \\
\hline $\begin{array}{l}\mathrm{B} 21 \\
{ }_{\mathrm{B} 22}\end{array}$ & $\begin{array}{l}80-100 \\
80=150 \\
140-15\end{array}$ & $\begin{array}{l}91,0 \\
91,0 \\
76,9\end{array}$ & $\begin{array}{l}1.0 \\
6.7\end{array}$ & $\begin{array}{l}0.2 \\
0.2\end{array}$ & $\begin{array}{l}2,1 \\
2,5 \\
6,5\end{array}$ & $\begin{array}{l}2 ., 7 \\
7.3\end{array}$ & $\begin{array}{l}1,7 \\
1,6\end{array}$ & $\begin{array}{l}0.9 \\
0.8\end{array}$ & $\begin{array}{l}5.30 \\
4.55\end{array}$ & $\begin{array}{l}0.458 \\
0.385\end{array}$ & $\begin{array}{l}11,6 \\
11,8\end{array}$ & $\begin{array}{l}5.54 .2 \\
5.94 .2\end{array}$ & $\begin{array}{l}0,12 \\
0,12\end{array}$ & $\begin{array}{l}0.06 \\
0,06\end{array}$ & $\begin{array}{l}0,01 \\
0,01\end{array}$ & $\begin{array}{l}0.02 \\
0.02\end{array}$ & $\begin{array}{l}0.21 \\
0.21\end{array}$ & $\begin{array}{l}2,0 \\
2,0\end{array}$ & & $\begin{array}{l}0.070 \\
0.055\end{array}$ & & & & & & & & \\
\hline 4. ${ }_{A 3}$ & $0-15$ & $\begin{array}{l}82.9 \\
872\end{array}$ & 1.1 & 0.2 & $\begin{array}{l}3,1 \\
3,7\end{array}$ & 7,1 & 2,0 & 3.6 & $\begin{array}{l}20.9 \\
{ }_{20.9}\end{array}$ & 1.49 & $\begin{array}{l}14,0 \\
0.0\end{array}$ & 4.73 .8 & $\begin{array}{l}0.24 \\
0.18\end{array}$ & $\begin{array}{l}0.18 \\
0.06\end{array}$ & $\begin{array}{l}0,03 \\
0,02\end{array}$ & $\begin{array}{l}0,02 \\
0,02\end{array}$ & $\begin{array}{l}0.47 \\
0.28\end{array}$ & $\begin{array}{l}8.0 \\
6.0\end{array}$ & $\begin{array}{l}1,55 \\
1,55\end{array}$ & $\begin{array}{l}0.180 \\
0.110\end{array}$ & $\begin{array}{l}0,045 \\
0,005\end{array}$ & $\begin{array}{l}3.20 \\
3.30\end{array}$ & $\begin{array}{l}2.75 \\
2.87\end{array}$ & $\begin{array}{l}0,11 \\
0,11\end{array}$ & $\begin{array}{l}0.02 \\
0.02\end{array}$ & $\begin{array}{l}0.02 \\
0.02\end{array}$ & $\begin{array}{l}0.14 \\
0,13\end{array}$ & $\begin{array}{l}1,61 \\
1,58\end{array}$ \\
\hline 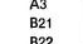 & $\begin{array}{l}20-30 \\
40-50\end{array}$ & $\begin{array}{l}87.2 \\
88,5\end{array}$ & $\begin{array}{l}1,0 \\
1,0 \\
10\end{array}$ & $\begin{array}{l}0.2 \\
0.2\end{array}$ & $\begin{array}{l}2.7 \\
2,8\end{array}$ & $\begin{array}{l}4.7 \\
4.6\end{array}$ & $\begin{array}{l}1.8 \\
1.7\end{array}$ & $\begin{array}{l}2,4 \\
1.2\end{array}$ & $\begin{array}{l}13,9 \\
6.76\end{array}$ & & 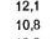 & 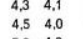 & $\begin{array}{l}0.16 \\
0.18 \\
0.18\end{array}$ & $\begin{array}{l}0.00 \\
0.06 \\
0.06\end{array}$ & $\begin{array}{l}0.02 \\
0.03 \\
0.02\end{array}$ & $\begin{array}{l}002 \\
0.02\end{array}$ & $\begin{array}{l}0.29 \\
0.28\end{array}$ & $\begin{array}{l}3,5 \\
2.0\end{array}$ & 1.25 & $\begin{array}{l}0.055 \\
0.035\end{array}$ & 0.007 & 3,30 & 2,85 & 0.12 & 0.02 & 0,02 & 0,16 & 5,10 \\
\hline${ }^{822}$ & & & & & & & & & & & & 524.0 & & & & & & & & & & & & & & & & \\
\hline
\end{tabular}

pag 60 a 